\title{
Areas de actividad y arquitectura doméstica en el poblado de Pubrisa durante la influencia incaica ${ }^{1}$
}

\section{RESUMEN}

El análisis de la arquitectura generada durante el Período Inca en el asentamiento de Pubrisa, y de los pisos de ocupación de seis recintos excavados, permitió definir el patrón arquitectónico local y determinar cómo interviene en él el estilo arquitectónico incaico. Además, se pudo reconocer el espacio doméstico al interior de las viviendas. Estas evidencias nos permiten proponer nuevas interpretaciones acerca de la función de este asentamiento.

Palabras claves: asentamientos - arquitectura - áreas de actividad - Período Inca - valle de Azapa.

\begin{abstract}
The analysis of both the architecture generated during the Inca Period in Pubrisa settlement, located about $1600 \mathrm{~m}$ in Azapa Valley, Northern Chile, and of the living floors of six excavated enclosures, allowed us to define the local architectonic pattern and the way in which it interyields the Inca architectonic style. In addition, the analysis let us recognize the domestic space within the houses. These evidences enable us to propose new interpretations about the function of this settlement.
\end{abstract}

Key words: settlements - architecture - activity areas - Inca Period-Azapa Valley.

Recibido: marzo 2007. Aceptado: agosto 2007.

\section{Introducción}

En todos los tiempos las sociedades han concebido a la arquitectura como uno de sus más valiosos signos de prestigio e identidad cultural, y su evolución y desarrollo reflejan la forma de pensar, de ser y de sentir de esas sociedades. Desde el punto de vista teórico se entiende que el lugar que el hombre elige para vivir debe ofrecer respuestas y soluciones que se acomoden a su forma de vida; será, en consecuencia,

1 Este artículo es resultado del Proyecto FONDECYT 1040296.

2 Departamento de Antropología, Universidad de Tarapacá. Casilla 6-D, Arica, CHILE.Email: imunoz@uta.cl; jchacama@ uta.cl un espacio que presente las mejores condiciones para su subsistencia y la de su grupo. Según Starker (1967), los pueblos del desierto han construido sus viviendas de acuerdo a su cultura, dando lugar a una variedad de tipos de residencias, las que están determinadas por el patrón de asentamiento. En el caso de los valles de Atacama, el hombre aprovechó de la mejor forma los recursos naturales existentes, por ejemplo, en los valles altos el material constructivo fundamental fue la piedra, la que se utilizó en estructuras de diferentes formas, tamaños y funciones, a diferencia de los valles bajos donde se construyó con caña y arcilla. De este modo, el uso de los diferentes espacios ecológicos contribuyó a crear formas arquitectónicas que son producto y reflejo de las comunidades que los habitaron y de las materias primas que utilizaron.

Una de las características fundamentales del asentamiento humano son las áreas de actividad que lo conforman. Manzanilla (1986: 9) señala que éstas constituirían la unidad mínima o primer nivel con sentido social dentro del registro arqueológico, y que pueden hallarse fuera o dentro del espacio habitacional (Barba y Manzanilla 1987). Willey (1953) discute el significado sociocultural del área de actividad, el que alcanza importancia en la distribución y organización interna del espacio habitable, que correspondería a toda actividad generada por el hombre reflejando un proceso de trabajo con consumo particular. El segundo nivel que sigue al área de actividad correspondería a la unidad habitacional (Manzanilla 1986), también denominada unidad doméstica (Wilk y Ashmore 1988), unidad residencial (Willey 1953) o household (Flannery 1976). En estas unidades de análisis el grupo familiar se interrelaciona tanto en el interior de sus moradas como fuera de ellas, en espacios en los que además pudieron haber interactuado con otros grupos familiares, logrando la organización e interacción de los diversos componentes humanos en el contexto de la vida cotidiana y ceremonial.

De acuerdo a lo anteriormente planteado, nuestra hipótesis de trabajo es que las áreas domésticas en el asentamiento de Pubrisa representan distintas áreas 
funcionales concebidas en forma planificada, integrando armónicamente tanto arquitectura doméstica como arquitectura ceremonial, e incluyendo espacios públicos. Para discutir esta hipótesis, nuestro objetivo fue reconstruir el espacio social a través del estudio de seis recintos excavados. Estos corresponderían a una kallanka, definida por Muñoz y Santos (2000) como cabildo, y cinco recintos habitacionales, todos ubicados en el centro del poblado.

La metodología utilizada ha sido previamente descrita (Muñoz 2004: 57-58); sin embargo, explicitaremos brevemente algunos pasos metodológicos en el trabajo de campo y en el análisis de los componentes químicos de las muestras. En el trabajo de campo se realizaron los siguientes pasos: a) despeje del área de estudio; b) descripción de los recintos, considerando los lineamientos arquitectónicos, técnicas de pircado, cimiento, mampostería, materiales utilizados en la construcción, acceso y vías de desplazamientos. Definido el sistema constructivo de la vivienda se realizó: c) un registro visual del piso ocupacional interno, intentando detectar testimonios de muros, postes y techumbres que conformaron la estructura física de la vivienda. El espacio excavado se dimensionó a través de cuadrantes, lo que permitió definir los componentes estructurales de la vivienda así como el material empleado. Posteriormente: d) se tomaron muestras de fogones (de $150 \mathrm{gr} \mathrm{c} / \mathrm{u}$ ) y de restos de desperdicios: e) también fueron tomadas como referencia muestras de suelo aledañas a la excavación, no alteradas por las actividades realizadas por los ocupantes del asentamiento. f) El análisis químico siguió el proceso establecido por Barba y Córdova (1999) para determinar fosfatos, carbonatos, potencial de hidrógeno $(\mathrm{pH})$, color, residuos proteicos y ácidos grasos.

Previamente, uno de los autores ya ha comentado los estudios sobre patrones de asentamiento en los Valles Occidentales (Muñoz 2005: 324-326) basándose en las discusiones sobre dicha problemática realizadas por Kolata (1989), Aldenderfer (1993), Kaulicke e Isbell (2001) y Muñoz y Chacama (2006). De ello se concluyó que las poblaciones del Intermedio Tardío y Tardío en los Andes Centro Sur construyeron distintos tipos de asentamientos desde el punto de vista arquitectónico, algunos más complejos como los que se ubican en los alrededores del lago Titicaca con templos, plazas, recintos habitacionales para albergar a un mayor número de gente, a diferencia de los asentamientos que se ubican en el altiplano meridional y valles occidentales, que presentan una arquitectura y distribución de los espacios al interior de los recintos de manera simple.

\section{El asentamiento}

El sitio arqueológico de Pubrisa se ubica a $45 \mathrm{~km}$ al interior de Arica, sobre un tablazo en la ladera este del valle de Azapa, a unos $30 \mathrm{~m}$ sobre el lecho del río. El lugar es también conocido por los lugareños como quebrada de Livilcar. El sitio se conforma por un conjunto de recintos de planta circular como rectangular, los que fueron construidos sobre sucesivos aterrazamientos artificiales del terreno con sus respectivos muros de contención, los que en muchas ocasiones se confunden con las paredes de los recintos.

El sendero de acceso dividió al sitio en dos, dejando hacia el sur los recintos circulares concentrados mayormente en la parte inferior del anfiteatro y sobre el cono de deyección; y hacia el norte, los recintos de planta rectangular, que en las cotas más bajas se mezclan con algunos recintos de planta circular (Figura 1).

Los sucesivos aterrazamientos son más claros en el sector norte donde se encuentran las construcciones de planta rectangular. En este sector, dichos aterrazamientos se crearon nivelando la superficie de la pendiente, ya sea sacando tierra o incorporando material de relleno, y conteniéndolos con muros que también podían constituir la parte exterior o posterior de un conjunto de recintos alineados. En algunos casos, entre los muros exteriores de un nivel superior y los muros posteriores del nivel inferior, quedó un espacio de 2 a $3 \mathrm{~m}$ de ancho, constituyendo pasillos de circulación aterrazados (Figura 2).

En el sector sur, los aterrazamientos son menos evidentes ya que son producto de la nivelación del terreno que se hizo para construir las estructuras de planta circular; no obstante, es posible notar una cierta alineación de estas estructuras, que da la idea de un aterrazamiento que sobrepasa el tamaño individual de cada una de ellas. Por otra parte, los muros de contención del sector norte parecieran prolongarse hacia el sur a través de los muros del conjunto de estructuras circulares emplazadas en un mismo nivel. Sobre este último punto volveremos más adelante.

Como referente para describir el sitio utilizaremos el sendero de acceso que recorre el lugar hasta los 


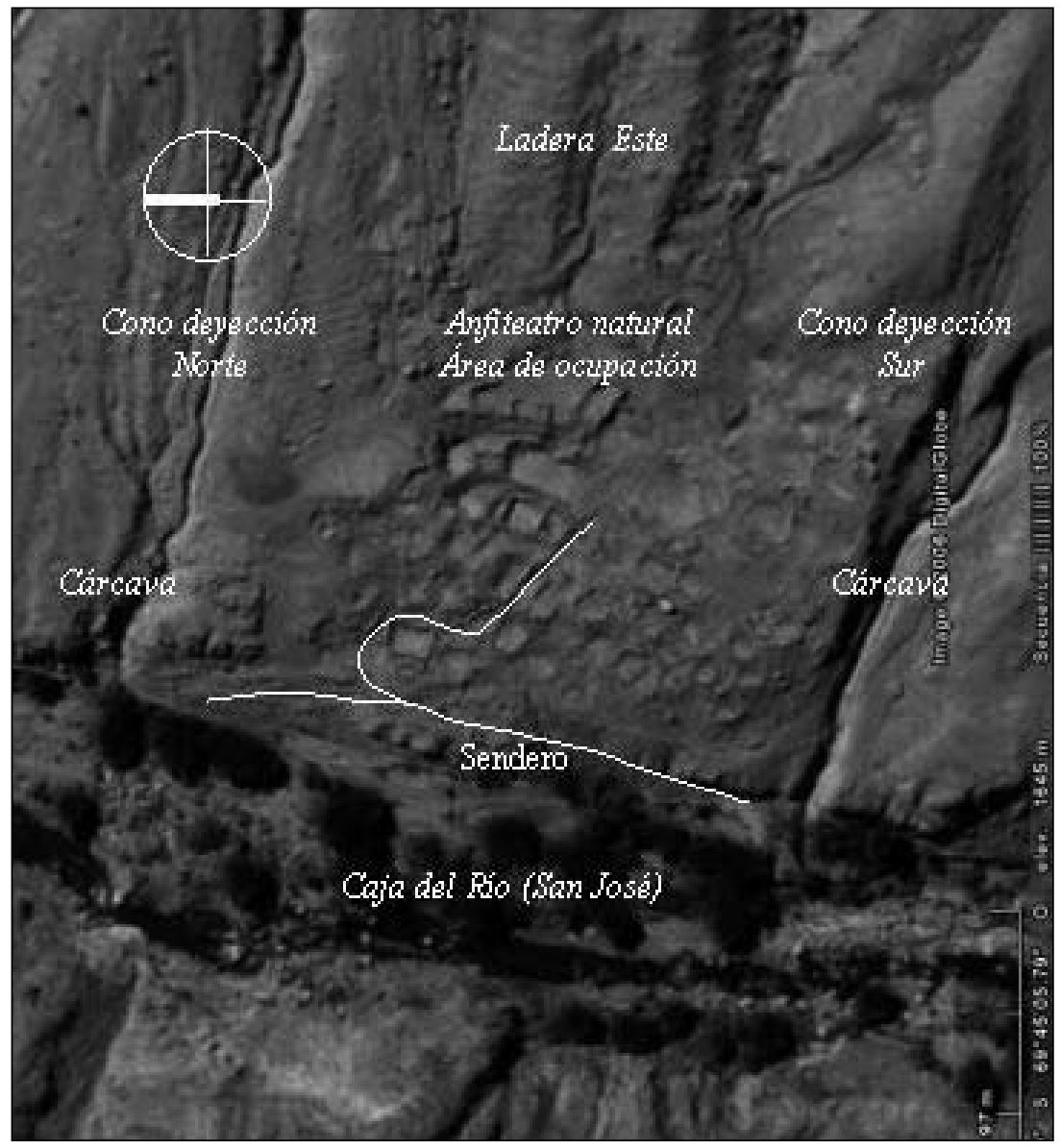

Figura 1. Fotografía aérea del sitio Pubrisa.

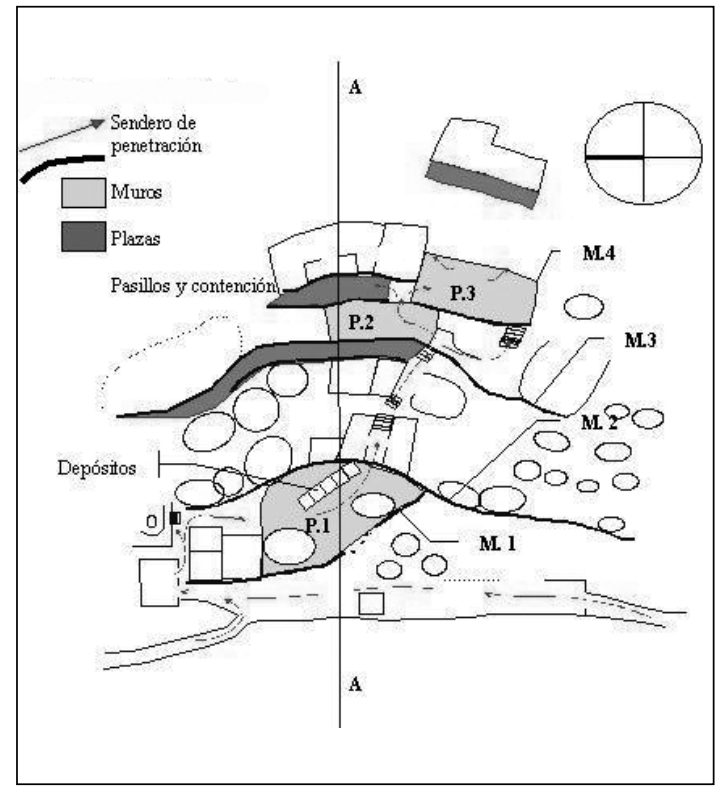

Figura 2. Esquema del sitio Pubrisa.

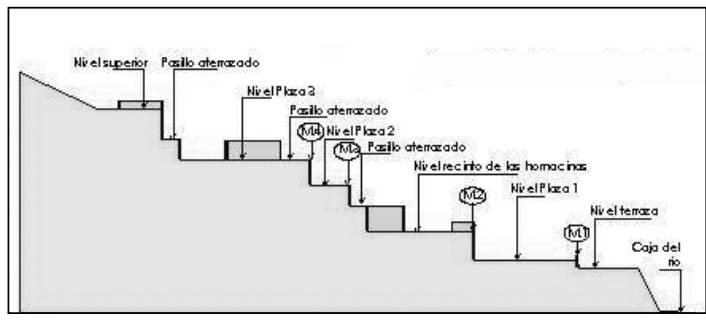

Figura 3. Corte del sitio Pubrisa.

aterrazamientos más altos, y los distintos niveles de éstos (Figura 3). La descripción del conjunto tenderá a focalizarse más en el sector norte, ya que éste presenta detalles constructivos y edificaciones más complejas que las existentes en el sector sur.

\section{Accesos}

El acceso al sitio desde el sur se realiza a través de un sendero sobre una rampa inclinada de unos $35^{\circ}$ de pendiente que asciende desde el río hasta 
la terraza fluvial, pasando por un umbral formado por dos pequeños muros de unos $2 \mathrm{~m}$ de largo. Desde allí, el sendero continúa por dicha terraza en forma paralela al valle, hasta llegar al acceso norte, que de igual forma está constituido por una pendiente aunque levemente más empinada. En el tramo intermedio, el sendero pasa por el costado de dos estructuras: una rectangular y otra circular, que, al parecer, corresponden a instalaciones subactuales.

El sendero de acceso por el norte es más angosto, siendo flanqueado por dos muros en una especie de pasillo: hacia la barranca una pirca de aproximadamente $1 \mathrm{~m}$ de altura y hacia el cerro un muro que constituye el primero del sitio (M1). Este perímetro corre paralelo al pasillo de ingreso, para luego presentar una forma semicircular que remata en el segundo muro perimetral, delimitando y conteniendo una explanada superior (ver Figura 1). Una escalinata de tres peldaños introduce en una plataforma rectangular circundada por un muro perimetral del cual sólo quedan sus bases. Desde dicha plataforma el sendero sigue la dirección de la pendiente del cerro. A su costado derecho o sur se hallan dos edificios de planta rectangular adosados uno al otro. A su izquierda y pasada la primera estructura rectangular se encuentra una estructura con dos escalones de cerca de $1 \mathrm{~m}$ de alto cada uno. Al llegar a esta estructura escalonada el sendero se formaliza en una escala con peldaños cada un metro de distancia. Casi al final de esta estructura se bifurca hacia el norte y hacia el sur en forma perpendicular. Hacia el norte, enfrenta la estructura escalonada en forma de una escala bien pronunciada de cuatro gradas, cuyo término se encuentra en el primer gran escalón de la estructura comentada. Por la erosión del sitio, no es posible percibir a simple vista si estas gradas continúan hacia el segundo escalón de la estructura.

La estructura mencionada tiene visibles dos lados de sus dos escalones: uno lateral, que sirve de muro al sendero-escala que estamos describiendo, y otro frontal de forma curva que mira al valle y es de forma curva. Los otros dos muros de la estructura no existen debido a que ésta se encuentra empotrada en el cono de deyección norte. En su plataforma superior hay un gran agujero de cerca de $1.5 \mathrm{~m}$ de diámetro y poco más de $1 \mathrm{~m}$ de profundidad. En su parte inferior, pese a estar muy alterado, el diámetro es ostensiblemente menor conservando aún parte de un recubrimiento de pirca, permitiendo proyectar un diámetro de 80 $\mathrm{cm}$. Dos metros al este del pozo, se encuentra una piedra paralepípeda dispuesta intencionalmente en la superficie de la estructura.

\section{Los aterrazamientos}

El primer nivel de aterrazamiento y la primera plaza. Hacia el sur, el sendero de acceso continúa entre el muro oeste de los dos recintos rectangulares descritos anteriormente y un gran muro muy destruido, que forma parte del segundo muro del sitio (M2). Pasando este tramo encontramos una explanada abierta o primera plaza delimitada por el sur por el muro semicircular destruido, que señaláramos anteriormente como M1. Dos grandes recintos circulares de casi $8 \mathrm{~m}$ de diámetro cada uno se distribuyen en la explanada. El primero, adosado al arco del primer muro, está en una cota más baja que la superficie de la explanada $(1.5 \mathrm{~m})$ $y$ tiene un acceso en forma de coma con gradas internas. El segundo recinto se encuentra adosado al término del arco formado por el primer muro y a un costado del segundo muro; está en la misma cota de la explanada y no se observa en él ningún vano de acceso. Es necesario hacer notar que parte de este sector bajo del sitio fue ocupado en épocas subactuales, lo que causó modificaciones en el uso $\mathrm{y}$ forma de varias estructuras.

En el sector este de la explanada y frente al segundo recinto circular se encuentra un conjunto de cinco estructuras cuadrangulares de unos $4 \mathrm{~m}^{2}$ cada una, adosadas entre sí. El conjunto se dispone en forma inclinada al segundo muro, terminando en él. La cara externa y la superficie interna de cada estructura tienen su base en el nivel de la explanada, mientras que la cara posterior llega al nivel de una pequeña terraza.

$\mathrm{Al}$ centro de su cara posterior y al tope de ésta, las cinco estructuras presentan una abertura definida por un pequeño vano. Este está revestido de piedras, tanto en sus partes laterales como en su base. Una estructura aislada sin mayores alteraciones similar a las descritas pero ubicada en los niveles altos del sitio, nos permitió visualizar la forma original de estas cinco estructuras (Figuras 4 y 5). Según ésta, las cinco estructuras en línea, adosadas una a otra, debieron haber sido depósitos o collcas destinadas a almacenar excedentes productivos. Estos depósitos son entonces parte integrante del conjunto de estructuras que conforman la primera plaza del sitio (ver Figura 2). 


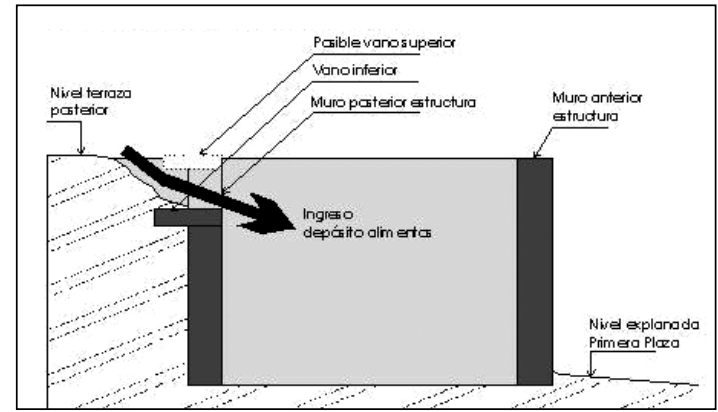

Figura 4. Esquema hipotético de la forma de depósito. Perfil en corte A-A.

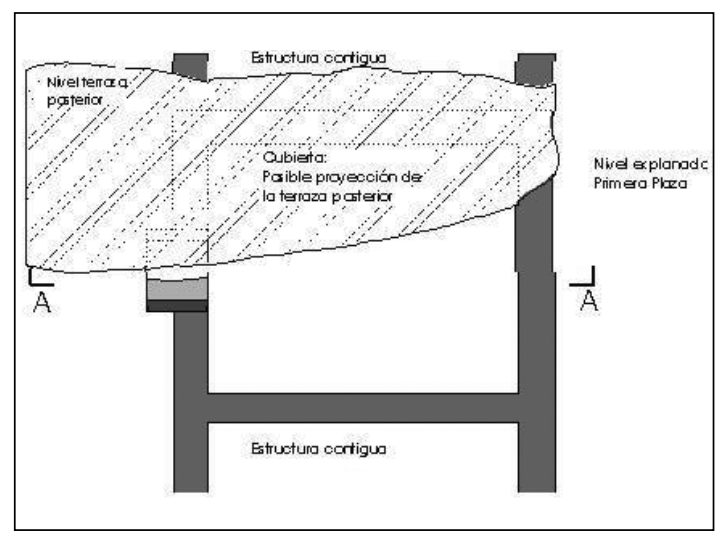

Figura 5. Esquema de planta de depósito con hipotética proyección de cubierta.

El segundo nivel de aterrazamiento. Entre las collcas y el recinto circular ubicados en la primera plaza se proyecta un umbral señalado por dos mochetas, prolongación del muro que delimita este segundo nivel. El sendero ingresa a este segundo nivel pasando entre dos grandes edificaciones rectangulares con sendos vanos de acceso que miran hacia el sendero. Avanzando unos metros, el sendero toma la forma de una escala empedrada que accede a una plataforma en la parte posterior de los dos recintos señalados y a la altura de sus muros posteriores, la que da origen a este segundo nivel (Figura 6).

En términos generales, este nivel sigue la forma general del sitio, como un anfiteatro. Hacia el norte del sendero de acceso se hallan dos grandes edificios rectangulares, uno de ellos con hornacinas en sus muros interiores, al que hemos denominado kallanka o cabildo, según información proporcionada por el pastor Francisco Chambi (Muñoz y Santos 2000). A continuación, se sitúan grandes recintos circulares. Hacia el sur del sendero encontramos recintos circulares un tanto destruidos por la erosión. Por el

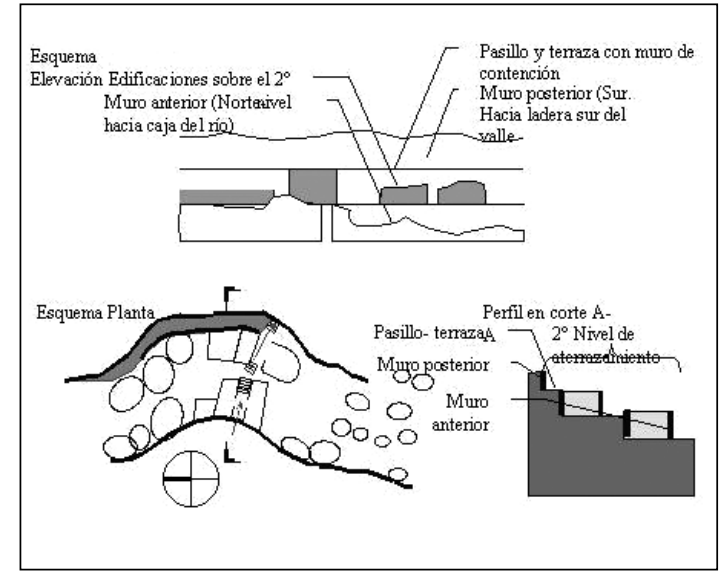

Figura 6. Esquema, planta, elevación y perfil en corte del segundo aterrazamiento.

oeste, este conjunto de edificaciones está contenido por el muro descrito en el párrafo previo, y por el este, por el muro que delimita el nivel superior. Este último, en su tramo este, se compone por la parte posterior de los edificios, por una pequeña terrazapasillo y por el muro que contiene el nivel superior (ver Figura 6).

Volviendo al sendero de acceso, éste se proyecta adosado a los recintos rectangulares construidos en la terraza de este segundo nivel y asciende en forma de gradas hacia el tercer nivel donde se emplaza un gran espacio abierto delimitado por un muro perimetral y que denominamos segunda plaza. Actualmente lo que pudo ser un vano de conexión entre la plaza y el acceso escalonado se encuentra cerrado por bloques posiblemente de data subactual, que otorgaron una nueva función al espacio.

El tercer nivel de aterrazamiento y la segunda plaza. Este nivel está definido casi completamente por un gran espacio delimitado por un muro perimetral (ver Figura 2). En el sector sur de este espacio hay algunos recintos circulares poco definidos. Un pozo de sondeo realizado en este sector mostró un relleno de más de $1 \mathrm{~m}$ de espesor con material cultural y restos orgánicos, especialmente vegetales. Es posible que el relleno sea parte del proceso de construcción del sitio, evidenciando que en dicho sector habría más irregularidades topográficas. Posiblemente existieron cárcavas que necesitaron de un relleno adicional para ser incorporadas al plan general del sitio. Por las características del terreno, el continuo proceso de erosión ha socavado este sector con mayor intensidad provocando el derrumbe de muros. 
Hacia el norte de la plaza se observan algunos recintos de planta rectangular. La plaza define el ancho de cerca de $15 \mathrm{~m}$ de este nivel. Su muro anterior es parte del muro de contención que da paso a este tercer nivel. Su muro posterior presenta similar característica al muro posterior del segundo nivel, es decir, está conformado por el muro de la plaza, una angosta terraza-pasillo y el muro de contención del nivel superior. Este tipo de construcción, al igual que en el nivel anterior, no abarca toda la amplitud del nivel, ubicándose en el sector norte del sitio; hacia el sector sur, ya sea por los socavamientos o por derrumbes de muro, no se aprecia este muro doble.

Un rasgo arquitectónico notable es que la terrazapasillo, al llegar al centro de la plaza presenta una grada que desciende hacia ella; frente a esta grada, hay otra que desciende de la plaza situada inmediatamente sobre la mencionada, en el último nivel de aterrazamiento. Ambas gradas se enfrentan y se unen en una tercera más ancha, que cambiando de dirección desciende directamente sobre la plaza descrita. En todo este sector se aprecian algunas mochetas muy derrumbadas que realzan este ingreso (Figura 7).

Aterrazamiento y la tercera plaza. Similar al tercer nivel, éste es un espacio de grandes dimensiones delimitado por un muro perimetral de baja altura y que hemos denominado tercera plaza. Se ubica preferentemente hacia el sector sur del sitio. Hacia el sector norte hay recintos rectangulares de grandes dimensiones; uno de ellos, que sirve de muro de

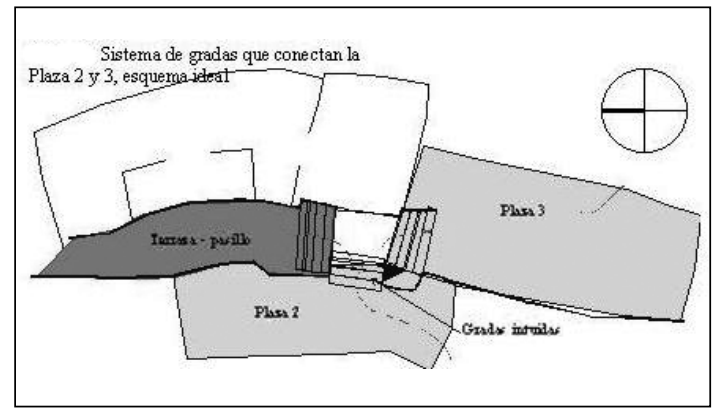

Figura 7. Esquema hipotético del sistema de gradas que conecta las plazas 2 y 3 .

delimitación de la plaza, alcanza los $8 \mathrm{~m}$ de largo y unos $4 \mathrm{~m}$ de ancho, y es posible apreciar una altura superior a $\operatorname{los} 2 \mathrm{~m}$.

La plaza en sí, de tamaño similar a la del nivel anterior, presenta algunos arreglos constructivos que la distinguen del resto: fuera del elaborado sistema de gradas descrito anteriormente (ver Figura 7), esta plaza presenta en su muro este dos escalinatas que cubren la altura del muro (1 m). Ambas se encuentran empotradas en el muro y conforman una unidad con él. Un tercer elemento arquitectónico consiste en un podio, también empotrado en el muro, ubicado casi al centro del muro sur. Estos tres elementos, por su técnica de construcción y ubicación, debieron ser concebidos en el mismo momento en que se planificó la construcción de la plaza, y los que unidos al complejo sistema de gradas ya señalado, le otorgan especiales características a este espacio (Figura 8).

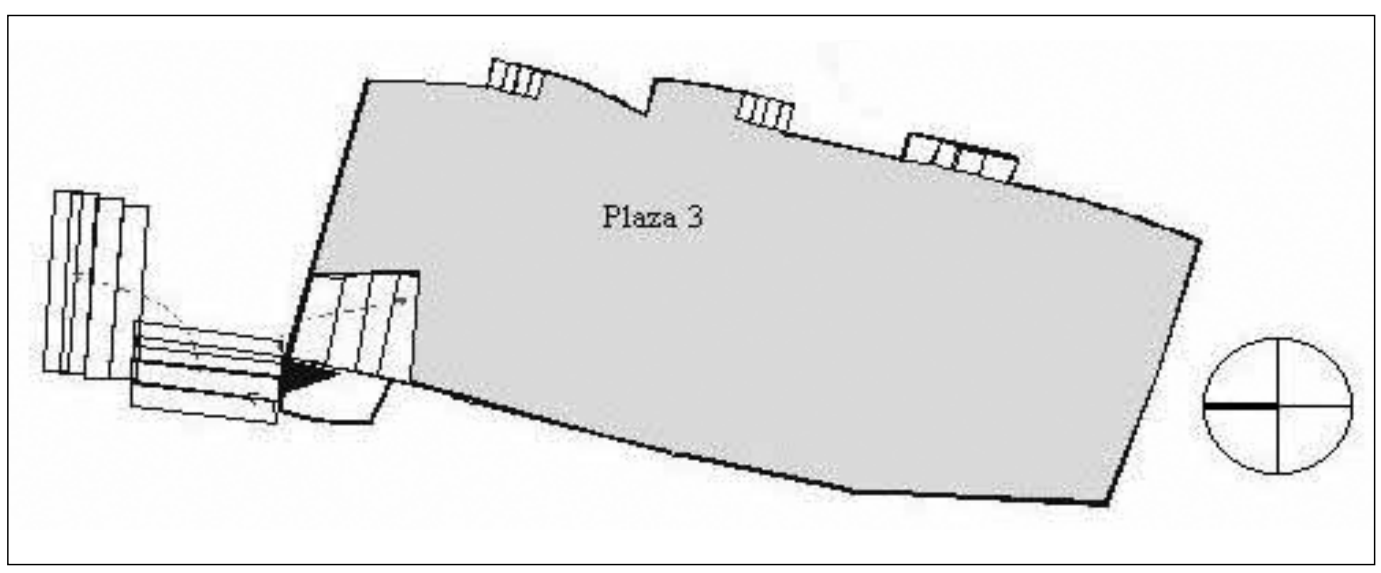

Figura 8. Esquema de la Plaza 3. 
El cuarto nivel de aterrazamiento. Finalmente, subiendo las escalinatas de la tercera plaza, nos encontramos con una explanada de unos $5 \mathrm{~m}$ de ancho que abarca todo el sitio a lo ancho; esta explanada a primera vista pareciera ser "un descanso" en la pendiente del cerro, pero por su uniformidad es probable que se trate de una terraza artificial. Una vez iniciada nuevamente la pendiente, en el sector inmediato tras la tercera plaza se encuentra un edificio con un muro de más de $2 \mathrm{~m}$ de altura en su cara oeste, sostenido por un muro de contención a manera de poyo de $1 \mathrm{~m}$ de alto y $1 \mathrm{~m}$ de ancho. Una visión superior del mismo edificio da cuenta que éste está constituido por tres recintos: dos en hilera sobre el muro alto y uno perpendicular a éstos, adentrándose en la pendiente del cerro; desde esta posición los muros sólo son percibidos como las bases de la edificación presentando una altura no mayor a $1 \mathrm{~m}$.

\section{Los recintos}

Las excavaciones se centraron en seis recintos; cinco de ellos presentan formas semicirculares a ovaladas, y en su interior se halló cerámica Gentilar-Pocoma, Saxamar, Chilpe y Engobes Negro sobre Rojo. El recinto 209 es de forma rectangular, con hornacinas y estuco en sus paredes; sin embargo, presenta los mismos estilos de cerámica de los recintos que tienen forma semicircular. Esto nos permite sugerir que ambas formas de recintos fueron ocupadas en forma sincrónica, es decir, la presencia de una población local (Gentilar-Pocoma, Chilpe) que coexistió con aquella de influencia inca (Saxamar y Engobes Negro sobre Rojo).

Recinto 182. Ubicado en el sector medio del asentamiento, es de forma semicircular y está conformado por un muro de doble hilada de piedra y tiene el acceso por el sector oeste. Su diámetro es de $7 \mathrm{~m}$ $\mathrm{y}$ tiene un muro de división conformado por doble hilera de piedras. El estrato de basura es de $7 \mathrm{~cm}$ de espesor, en él se hallaron restos de alfarería decorada y no decorada, fragmentos de conchas de Choromytilus y Concholepas, huesos de mamíferos terrestres, semillas de calabazas, zuros de maíz, restos de fogones y cenizas, un fragmento de batán y una mano de moler.

Recinto 209. Se ubica en el sector medio del asentamiento. Es un recinto bien conservado, de forma rectangular, conformado por un muro de doble hilada de piedra y un diámetro de $9 \mathrm{~m}$. Estos muros alcanzan $1.5 \mathrm{~m}$ de alto (Figura 9). En las paredes norte,

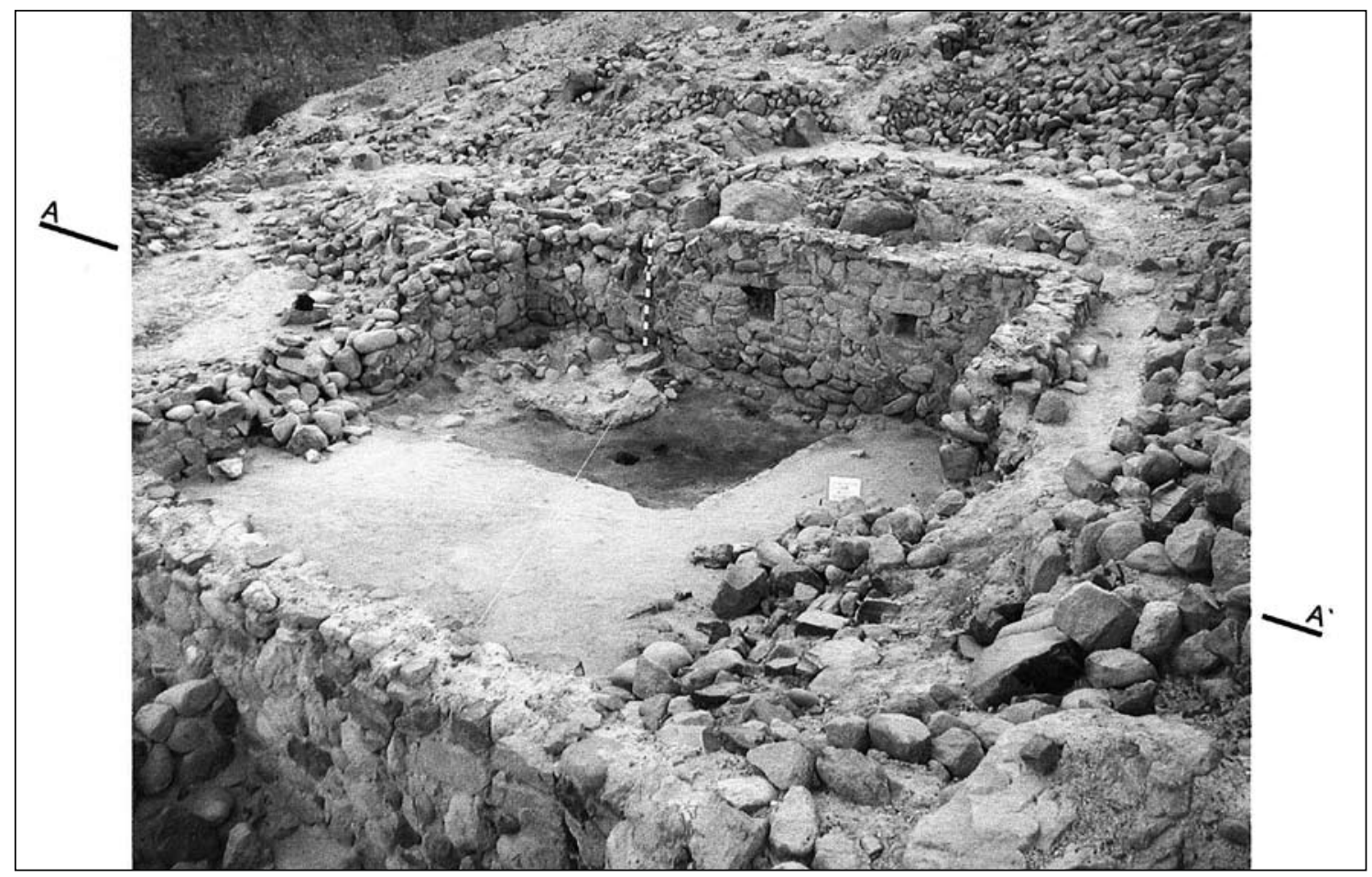

Figura 9. Recinto 209. Ocupación de piso ocupacional en vértice norte. 


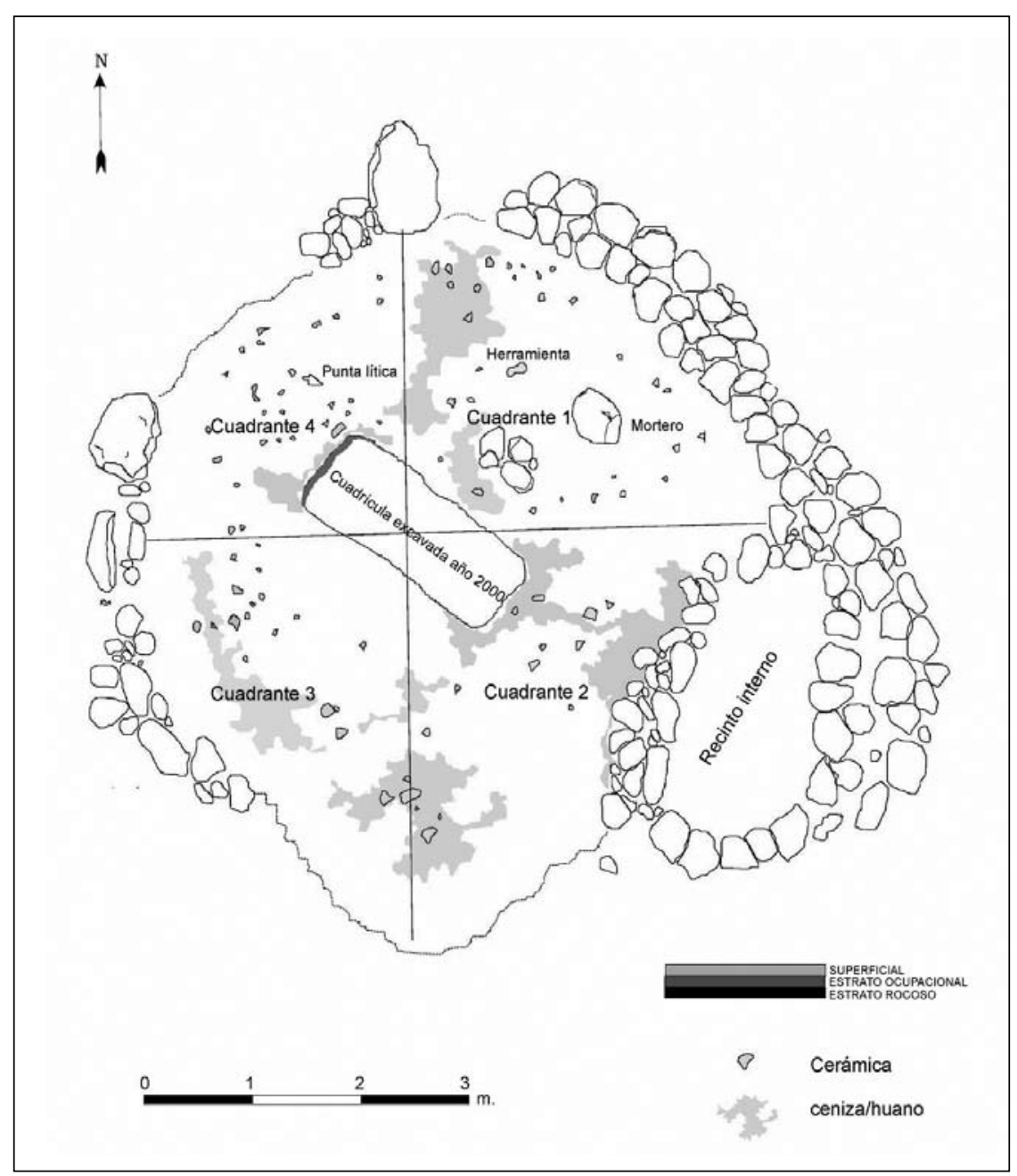

Figura 10. Recinto 236. Planta arquitectónica.

sur y este se hallan hornacinas bien conservadas, de $50 \mathrm{~cm}$ de ancho aproximadamente. El estrato de basura es de $6 \mathrm{~cm}$ de espesor y en él se hallaron fragmentos de alfarería no decorada con hollín en su superficie, restos de huesos, chorito, guano de camélidos y fragmentos de madera asociados a fogones y cenizas.

Recinto 236. Ubicado en el sector medio del asentamiento, es de forma semicircular y tiene muros abatidos. Uno de ellos es de doble hilada de piedras. El recinto tiene un diámetro de $6 \mathrm{~m}$ y un muro de división interior de $3 \mathrm{~m}$ conformado por una hilera de piedras (Figura 10). El acceso es por el sector noreste. El estrato de basura es de $8 \mathrm{~cm}$ de espesor y en él se hallaron restos de alfarería decorada y no decorada, fragmentos de tejidos sin decoración, sogas de lana y una pequeña punta de proyectil confeccionada en calcedonia; además, fragmentos de conchas de choritos, restos de camarones, huesos de camélidos y roedores, zuros de maíz, huesos de aves, coprolitos de camélidos, restos de fogones, cenizas y fragmentos de madera quemada.

Recinto 242. Ubicado en el sector medio del asentamiento, es de forma irregular semicircular ya que hay bastante abatimiento del muro, el cual es de doble hilada de piedra. Su diámetro es de $7 \mathrm{~m}$ y el acceso es por el sector oeste. El estrato de basura es de $6 \mathrm{~cm}$ de espesor y en él se hallaron restos de fogones y cenizas, además de fragmentos de conchas de Choromytilus, Concholepas y Mesodesmas (almejas), huesos de mamíferos terrestres, restos de camarón y de huesos de aves y mazorcas de maíz. También fueron hallados fragmentos de cerámica de estilo Charcollo, fragmentos de escudillas, 
cerámica no decorada con hollín en su superficie y dos fragmentos de batán.

Recinto 244. Ubicado en el sector central del asentamiento, es de forma subrectangular y con muros de doble hilada de piedra que presentan bastante abatimiento. Su diámetro es de $6 \mathrm{~m}$ y tiene un pasillo de acceso por el sector sur. El estrato de basura es de $5 \mathrm{~cm}$ de espesor y en él se hallaron restos de alfarería no decorada con hollín, restos de caracol y óseos, fragmentos de totora y de madera quemada asociada a fogones y cenizas.

Recinto 258. Ubicado en el sector medio del asentamiento, es de forma subrectangular conformado por un muro de doble hilada de piedra y un muro de división interior de una hilera de piedras. Su diámetro es de $6 \mathrm{~m}$. El estrato de basura es de $6 \mathrm{~cm}$ de espesor y en él se hallaron fragmentos de alfarería no decorada, zuros de maíz, totora, dos morteros cóncavos y tres batanes de superficie plana, además de huesos y guano de camélidos. Se hallaron cinco fogones distribuidos de sur a norte. En el sector noreste se halló una cocina hecha de piedras con una depresión en la parte central. Asociado a ésta se halló un poste de madera que aparece revestido con piedras pequeñas.

\section{Análisis y resultados}

En el interior de los recintos de Pubrisa pudimos reconocer áreas de actividad ligadas a la vida doméstica y ceremonial de sus pobladores, a través de los artefactos depositados, identificación de componentes químicos en los pisos de ocupación y rasgos arquitectónicos de los recintos excavados. Es así como de cada uno de ellos se tomaron dos muestras del piso de ocupación asociadas a fogón y residuos orgánicos y/o a cenizas y carbón, con el fin de realizar análisis de su composición química. Los resultados se detallan en la Tabla 1.

Con el análisis químico de las muestras de suelo se pudo determinar la realización de tres actividades domésticas en zonas determinadas de los recintos: a) zonas de preparación de alimentos, cuyos componentes básicos son fogones; el área presenta altos valores de $\mathrm{pH}$ que se correlacionan con concentraciones de cenizas y carbón, con bajos valores de fosfato, y en ocasiones, abundantes semillas carbonizadas; b) zonas de calentamiento sin concentraciones de fosfatos, residuos proteicos y ácidos grasos; c) zonas de consumo de alimentos ubicadas alrededor de las áreas de preparación de alimentos y normalmente presentan altos valores de fosfatos y un pH más bajo, además de residuos proteicos y ácidos grasos.

La preparación y consumo de alimentos quizás correspondan a las actividades más representativas generadas al interior de las viviendas. Las áreas en que se realizaron estas actividades están constituidas por desechos de alimentos, que en ocasiones aparecen asociados a fogones y cenizas. Algunos desechos corresponden a madera, conchas y restos de frutos sin identificar, calcinados, que constituyen claramente desechos alimenticios. Otros restos de basuras fueron huesos, cueros y lana de camélidos y productos de recolección y pesca marina, como crustáceos, mariscos y pescados; en grado menor hemos identificado restos de huesos de aves y roedores. Junto a los fogones hallamos morteros, generalmente batanes de superficie plana, que fueron empleados para la molienda de granos y raíces. Estos artefactos se hallan distribuidos en el centro y en espacios laterales del recinto, y en algunos casos, como el recinto 258 , corresponden a más de un artefacto (Tabla 2). Tenemos una sola evidencia de cocina en el recinto 242 , y consiste en una cavidad revestida con piedras que presentan hollín en su superficie. Las comidas fueron preparadas en ollas; la presencia de restos de alimentos adheridos en la superficie interior de los fragmentos de cerámica apoyarían esta hipótesis, a su vez, las jarras pudieron haber servido para trasladar agua y las escudillas para depositar y servir alimentos, especialmente granos, que es lo que se observa con mayor frecuencia en los estratos de basuras. Los keros, aunque escasos, pudieron haber sido utilizados para consumir líquidos especialmente en ceremonias y fiestas, ya que fueron hallados en la kallanka o cabildo, un espacio de mayor interacción social (Tabla 3).

Fuera de los fogones donde prepararon comidas, en algunos recintos, especialmente en sus esquinas, hemos podido determinar la presencia de fogatas, varias de ellas sin restos de alimentos, lo que sugiere que fueron hechas para calentarse; corresponden a restos de cenizas producto de la combustión de madera. Es probable que estas fogatas hayan estado vinculadas a los espacios donde la gente se acomodó para dormir. El análisis químico de estos pisos determinó la presencia de residuos grasos; además se 


\begin{tabular}{|c|c|c|}
\hline $\mathbf{N}^{0}$ Recinto & Muestra 1 & Muestra 2 \\
\hline \multirow{5}{*}{182} & $\begin{array}{l}\text { Asociada a fogón y residuos orgánicos: preparación de } \\
\text { alimentos }\end{array}$ & $\begin{array}{l}\text { Asociada a fogón y residuos orgánicos: preparación y con- } \\
\text { sumo de alimentos }\end{array}$ \\
\hline & Fosfato alto & Fosfato alto \\
\hline & pH bajo & pH bajo \\
\hline & Acidos grasos & Acidos grasos \\
\hline & Proteínas & Proteínas \\
\hline \multirow{5}{*}{209} & $\begin{array}{l}\text { Asociado a fogón y residuos orgánicos: preparación y con- } \\
\text { sumo de alimentos }\end{array}$ & $\begin{array}{l}\text { Asociado a cenizas y carbón: calentamiento y restos de } \\
\text { comidas }\end{array}$ \\
\hline & Fosfato alto & Fosfato bajo \\
\hline & pH bajo & pH alto \\
\hline & Acidos grasos & Acidos grasos \\
\hline & Proteínas & Proteínas \\
\hline \multirow{5}{*}{236} & $\begin{array}{l}\text { Asociada a fogón y residuos orgánicos: preparación de } \\
\text { alimentos }\end{array}$ & $\begin{array}{l}\text { Asociada a fogón y residuos orgánicos: preparación y con- } \\
\text { sumo de alimentos }\end{array}$ \\
\hline & Fosfato alto & Fosfato alto \\
\hline & pH bajo & pH bajo \\
\hline & Acidos grasos & Acidos grasos \\
\hline & Proteínas & Proteínas \\
\hline \multirow{5}{*}{242} & Sedimento gris con restos carbonizados: calentamiento & $\begin{array}{l}\text { Asociada a cenizas y carbón: preparación y consumo de } \\
\text { alimentos }\end{array}$ \\
\hline & Fosfato bajo & Fosfato alto \\
\hline & $\mathrm{pH}$ alto & pH bajo \\
\hline & Acidos grasos & Acidos grasos \\
\hline & Proteínas & Proteínas \\
\hline \multirow{5}{*}{244} & $\begin{array}{l}\text { Sedimento gris, cenizas y residuos orgánicos: preparación y } \\
\text { consumo de alimentos }\end{array}$ & $\begin{array}{l}\text { Sedimento gris, cenizas y residuos orgánicos: preparación y } \\
\text { consumo de alimentos }\end{array}$ \\
\hline & Fosfato bajo & Fosfato bajo \\
\hline & pH alto & $\mathrm{pH}$ alto \\
\hline & Acidos grasos & Acidos grasos \\
\hline & Proteínas & Proteínas \\
\hline \multirow{5}{*}{258} & Asociada a fogón y residuos orgánicos: calentamiento & $\begin{array}{l}\text { Asociada a cenizas y carbón: calentamiento y restos tos } \\
\text { de comidas }\end{array}$ \\
\hline & Fosfato bajo & Fosfato alto \\
\hline & $\mathrm{pH}$ alto & pH bajo \\
\hline & Acidos grasos & Acidos grasos \\
\hline & Proteínas & Proteínas \\
\hline
\end{tabular}

Tabla 1. Componentes químicos en los pisos ocupacionales.

\begin{tabular}{|c|c|c|c|}
\hline $\mathbf{N}^{\mathbf{0}}$ Recinto & Forma & Cantidad & Asociación \\
\hline 182 & Cónica & 1 & - \\
\hline 209 & - & - & - \\
\hline 236 & Plana (batán) & 1 & Mano de moler \\
\hline 242 & Plana (batán) & 1 & - \\
\hline 244 & Plana (batán) & 1 & Mano de moler \\
\hline 258 & Plana (batán) & 6 & Mano de moler \\
\hline
\end{tabular}

Tabla 2. Presencia de artefactos de molienda en los recintos excavados. encontraron restos de lana y cuero, lo cual apoyaría la hipótesis respecto de la función que habrían tenido estos espacios. En relación a ellos, es importante señalar que algunos fueron organizados en las esquinas ya que sus muros que se ubican debajo del estrato superficial aparecen con restos de hollín.

No está claro si retocaron o manufacturaron objetos en el interior de los recintos puesto que el número de artefactos hallados es bajo; sin embargo, la presencia de una punta de proyectil y un machacador 
en el recinto 236 sugiere que objetos como estos eran utilizados para cortar y golpear probablemente alimentos en los momentos de su preparación; distinto sería el caso de los instrumentos de labranza como una pala hallada en el recinto 236 que pudo haber sido retocada o pulida en el momento que el individuo se encontraba dentro del recinto.

Los artefactos de cerámica fueron los mejor representados en el sitio; sin embargo no se observa que hayan sido manufacturados en el interior de los recintos. Estilísticamente corresponden a los estilos Negro sobre Rojo, Chilpe, Saxamar y Gentilar-Pocoma (Tabla 3) cuyos fechados por termoluminiscencia los sitúan hacia fines del Período Intermedio Tardío y Tardío, y se asocian a una arquitectura Inca Regional.

\begin{tabular}{|c|c|c|c|c|}
\hline $\begin{array}{c}\mathrm{N}^{\circ} \\
\text { Recinto }\end{array}$ & Forma & $\%$ & Estilo & $\%$ \\
\hline \multirow[t]{5}{*}{182} & Ollas & 34 & Saxamar & - \\
\hline & Jarras & 8 & Chilpe & 1 \\
\hline & Keros & - & Negro sobre Rojo & 5 \\
\hline & Escudillas & 2 & Gentilar-Pocoma & - \\
\hline & Sin identificar & 56 & Sin identificar & 94 \\
\hline \multirow[t]{5}{*}{209} & Ollas & 23 & Saxamar & 1 \\
\hline & Jarras & 4 & Chilpe & - \\
\hline & Keros & 1 & Negro sobre Rojo & 2 \\
\hline & Escudillas & 2 & Gentilar-Pocoma & 1 \\
\hline & Sin identificar & 70 & Sin identificar & 96 \\
\hline \multirow[t]{5}{*}{236} & Ollas & 27 & Saxamar & - \\
\hline & Jarras & 6 & Chilpe & 2 \\
\hline & Keros & 1 & Negro sobre Rojo & 2 \\
\hline & Escudillas & 2 & Gentilar-Pocoma & - \\
\hline & Sin identificar & 64 & Sin identificar & 96 \\
\hline \multirow[t]{5}{*}{242} & Ollas & 21 & Saxamar & 1 \\
\hline & Jarras & 3 & Chilpe & 2 \\
\hline & Keros & 1 & Negro sobre Rojo & 2 \\
\hline & Escudillas & 2 & Gentilar-Pocoma & 1 \\
\hline & Sin identificar & 73 & Sin identificar & 94 \\
\hline \multirow[t]{5}{*}{244} & Ollas & 29 & Saxamar & - \\
\hline & Jarras & 5 & Chilpe & 3 \\
\hline & Keros & - & Negro sobre Rojo & 2 \\
\hline & Escudillas & 2 & Gentilar-Pocoma & - \\
\hline & Sin identificar & 64 & Sin identificar & 95 \\
\hline \multirow[t]{5}{*}{258} & Ollas & 21 & Saxamar & 1 \\
\hline & Jarras & 4 & Chilpe & 1 \\
\hline & Keros & - & Negro sobre Rojo & 1 \\
\hline & Escudillas & 1 & Gentilar-Pocoma & - \\
\hline & Sin identificar & 74 & Sin identificar & 97 \\
\hline
\end{tabular}

Tabla 3. Formas y estilos de cerámica en los recintos excavados.
Ahora, desde el punto de vista constructivo, desde el interior de los recintos se pueden observar ciertos elementos de importancia para la arquitectura incaica en la zona: la presencia de pisos de grava, material que probablemente sirvió para nivelar el piso de la kallanka (recinto 209), aspecto hasta ahora inédito en los sitios incaicos de los valles de Arica. Esta misma estructura, cuya conservación es buena, presenta hornacinas en sus paredes, lo que es típico de la arquitectura incaica. A su vez, en el interior de los recintos habitacionales observamos la construcción de pequeños recintos circulares que sirvieron para moler y prender fuego, así como pasillos de ingreso en el recinto 244 .

\section{Planificación del sitio y componentes arquitectónicos}

Para lograr una visión integral del asentamiento de Pubrisa como conjunto, primero caracterizaremos algunas estructuras arquitectónicas y espaciales como rasgos diagnósticos.

La disposición y el tipo de estructuras descritas indican que el sector conformado por un conjunto de recintos circulares constituye una típica aldea serrana del Período Intermedio Tardío, es decir, un conglomerado de recintos de planta circular construidos con técnica de mampostería en doble hilera, que dejan pequeños espacios entre ellos a manera de pasillos de circulación. Constituye este sector lo que caracterizasemos en su momento como aldeas serranas ubicadas en laderas de valles precordilleranos con un claro componente agrícola como eje de su economía (Muñoz et al. 1997; Chacama 2005; Muñoz y Chacama 2006).

En cambio, el sector norte con unidades de planta rectangular y sistemas de aterrazamientos, estaría asociado con la presencia incaica en la región. Esta dicotomía Intermedio Tardío-Tardío ya había sido visualizada en las primeras investigaciones del sitio durante la década de los 90 (Muñoz y Santos 2000). La presencia incaica aislada de los sitios locales del Intermedio Tardío o en la periferia de éstos es un modelo de asentamiento que se repite en diversos sitios de la precordillera de Arica (Muñoz et al. 1997; Chacama 2005; Muñoz y Chacama 2006), sólo que en el caso de Pubrisa la presencia incaica es casi equivalente a la superficie de las estructuras locales y de mayor complejidad que la observada en otros asentamientos incaicos de la zona. 
Con anterioridad ya hemos definido los criterios por los cuales caracterizamos parte del asentamiento de Pubrisa como perteneciente al momento incaico (Muñoz y Chacama 2006). Las exploraciones y excavaciones del sitio llevadas a cabo durante los últimos años en el marco del Proyecto FONDECYT 1040296 entregaron evidencias que nos permiten ratificar los planteamientos anteriores, así como ofrecer nuevas interpretaciones respecto de la función de este asentamiento.

Como dijimos previamente, la forma como se constituyó el sitio de Pubrisa pasa al menos por dos sucesivas etapas. La primera de ellas, una aldea conglomerada del Período Intermedio Tardío, caracterizada por recintos de planta circular, ubicada sobre la ladera de uno de los conos de deyección que cae sobre el área. La segunda etapa, asimilable a la presencia inca en la región, implica el emplazamiento en uno de los bordes de la aldea local, que se caracteriza por grandes recintos de planta rectangular, algunos de ellos de un evidente carácter ceremonial. Este conjunto ubicado en el sector norte del sitio fue, a nuestro entender, preconcebido antes de su levantamiento material y esta concepción intentó también involucrar en un mismo plan de asentamiento a la aldea local preexistente. Para apoyar esta hipótesis nos detendremos en el sendero de acceso y en los niveles de aterrazamiento.

El sendero de acceso puede considerarse como un eje conductor y el "único" medio que permite un tránsito fluido desde la base misma de la terraza donde se encuentra emplazado el sitio, hasta los niveles más altos. Hoy, por supuesto, es posible deambular por sus ruinas y atravesarlo por distintos lugares, no obstante, reconstruyendo las edificaciones en pie con sus respectivas alturas de muro, el sendero de acceso es la forma lógica para acceder a los distintos niveles de Pubrisa; desde él se desprenden accesos a los diferentes niveles de las terrazas. La presencia de este eje conductor, ubicado casi en medio del conjunto, refuerza la idea de una planificación o al menos de una concepción previa del sitio antes de su construcción.

Por otro lado, en la parte norte del sitio la confección de niveles de aterrazamiento que demandaron grandes volúmenes de material de relleno sugiere una planificación previa a su construcción. Tales aterrazamientos y sus correspondientes muros de contención producen niveles bien definidos dentro del conjunto; estos niveles presentan accesos con umbrales resaltados por algún recurso constructivo como mochetas o gradas, o ambos. En este sentido, y guardando las proporciones pertinentes, Pubrisa se asemeja a típicos patrones incaicos instalados sobre sistema de terrazas, como por ejemplo, aquellos existentes en el sistema fluvial Urubamba-Vilcanota (Bouchard 1983) o en centros urbanísticos distantes de Cusco (Gasparini y Margolies 1980).

Los niveles sucesivos de terrazas y los senderos con escalinatas que comunican dichos niveles son aspectos característicos en la planificación de diversos asentamientos inca, ya sea en la zona de Cusco o en otras zonas del Tawantinsuyo. En el caso de Pubrisa, su presencia acrecienta la idea de que su sector norte obedeció a una planificación previa, bajo los conceptos incaicos.

Un aspecto adicional de la planificación de Pubrisa bajo el dominio inca se puede observar a partir del umbral de acceso al segundo sistema de terrazas, ubicado en la primera plaza. Señalábamos que este acceso, escalinata de piedras, estaba resaltado por dos mochetas originadas por la extensión del muro frontal de dos edificios que flanquean el sendero; pues bien, hacia el norte, el muro frontal de uno de los edificios continúa en una línea recta, sirviendo de contención a la segunda terraza como, a su vez, es parte de las edificaciones allí existentes. Hacia el sur del sendero de acceso, el muro frontal del otro edificio se confunde con los muros perimetrales de un conjunto de recintos de planta circular, adosados uno a otro en un mismo nivel. Es difícil señalar con certeza si esta disposición fue un efecto intencional para provocar la integración de la aldea local al nuevo plan o sólo se trata de un efecto coincidente. Lamentablemente en esta zona, los muros perimetrales de las estructuras allí existentes se encuentran bastante derruidos y no es posible apreciar si se trata de un muro continuo o si es un efecto de la continuidad de recintos adosados.

Sin embargo, el hecho de que el sendero de acceso penetre este sistema de muros por un lugar central y resaltado por atributos arquitectónicos y dos edificios flanqueándolo, nos atrevemos a aventurar la hipótesis que la instalación inca pretendió incorporar a su plan de asentamiento a la aldea local, situación que se escapa de lo visto en la generalidad de los sitios con arquitectura incaica en la precordillera de Arica, en los cuales las instalaciones incaicas permanecen en los bordes de la aldea local o sencillamente apartadas de ésta. En este sentido, y como ya lo manifestamos 
anteriormente (Muñoz y Chacama 2006), el único símil que podemos asociar a Pubrisa en el norte de Chile es el sitio Turi en la Segunda Región.

\section{La estructura escalonada}

Sus características formales, con escalinata de acceso y agujero en su plataforma superior, nos han llevado a considerarla como un ushnu. La imagen tradicional que tenemos de la estructura incaica llamada ushnu nos remite a un asiento escalonado desde el cual el Inka o algunos de sus representantes presidieron un conjunto diverso de ceremonias. No obstante lo anterior, el concepto de ushnu es mucho más amplio y contempla una mayor diversidad de estructuras. De hecho, Zuidema (1989) señala que éste habría integrado varias "edificaciones", entre ellas el gnomon, columna o edificio que indicaba el paso del sol por el cenit; el escaño u asiento escalonado (generalmente identificado con el ushnu), donde se sentaba el Inka; la "pila" donde se vertían las ofrendas de chicha y el sacrificio de las capac hucha o capac cocha y algunos edificios importantes como el Cuyusmanco que habría sido un aposento involucrado tanto en los rituales como en las observaciones astronómicas que incidían en los procesos agrícolas llevados a cabo por el Estado. Por último, el concepto arquitectónico de ushnu involucraba la plaza (aukaipata) que contenía al espacio ritual (Zuidema 1989: 402-454).

En la precordillera de Arica una estructura tipo ushnu ha sido identificada en el sitio Saguara (Schiappacasse y Niemeyer 2002), y otra, al menos insinuada como tal, en el Tambo Chungara, en el altiplano de Arica (Aldunate 2001). Ambas estructuras, aunque arquitectónicamente diferentes, mantienen elementos comunes como un terraplén y una escala de acceso a éste. Con similares características, el ushnu de Cerro Verde en la II Región presenta igualmente diferencias formales: estructura escalonada con dos escalinatas laterales (Adán 1999; Adán y Uribe 2005). Los pocos ejemplos de ushnu existentes en el norte de Chile, si bien presentan algunos elementos comunes, difieren en su forma, no siguiendo por tanto un mismo patrón constructivo. En este contexto, la estructura escalonada de Pubrisa sería una muestra más de la versatilidad de este tipo de edificaciones: una estructura de dos niveles, empotrada en una ladera, con una escalinata lateral de acceso y un pozo o "pila" en su superficie. A estos tres elementos habría que sumar la presencia hipotética de una piedra de unos $80 \mathrm{~cm}$ de altura con características generales de un paralelepípedo, situado a unos $2 \mathrm{~m}$ del pozo en la superficie de la estructura: ¿serviría este elemento como señalizador del paso del sol por el cenit?

El ushnu en cuestión se ubica en el sendero de acceso al sitio Pubrisa. Señalábamos que luego de ingresar a través de una plataforma de acceso y siguiendo un pasillo con escalinatas, se llega a un costado de esta edificación, sector donde se encuentra la escalinata de acceso. Por lo tanto, el ushnu de Pubrisa corresponde a una de las primeras edificaciones de importancia a la cual accedería un lugareño o un visitante.

\section{Las plazas}

La gran mayoría de las aldeas y pucaras de la precordillera de Arica asociados a una población local presentan evidencias de espacios abiertos delimitados por grandes bloques y que se encuentran preferentemente en los bordes de las aldeas y frente al acceso de los pucaras. Aunque para el norte de Chile no son muchos los estudios sistemáticos sobre estos espacios, la literatura arqueológica los ha señalado como plazas y parecen haber estado vinculados a celebraciones en torno al culto de los ancestros. Aldunate y colaboradores (1979) proponen dicha actividad ritual en asociación a estructuras tipo chullpa en Likan, en la Segunda Región.

Del mismo modo, en el norte de Lípez y en la quebrada de Humahuaca en el Noroeste Argentino, Nielsen (2006) propone que las plazas del Período Intermedio Tardío se encuentran vinculadas al culto a los ancestros. Señala además que dicho culto en las plazas es indicador de actividades de gobierno descentralizado y apropiación corporativa de recursos. Según Isbell (1997), estas evidencias constituirían un conjunto de indicadores que sugieren una organización social tipo ayllu. Esta hipótesis la plantea con base en la documentación etnohistórica de los siglos XVI y XVII.

Sabemos por las crónicas que las plazas fueron uno de los espacios de mayor importancia en la función religioso-política y por ende administrativa del Tawantinsuyo. En ellas se celebraron la mayoría de los rituales del Estado y desde allí se promovió la organización política y social de éste. En dicho contexto, las plazas instaladas en ambiente lejanos al Cusco debieron desempeñar la misma función a escala local. Nielsen (2006) señala que éstas, a diferencia de la función local de la plaza con sus ancestros tutelares, habrían actuado en función de 


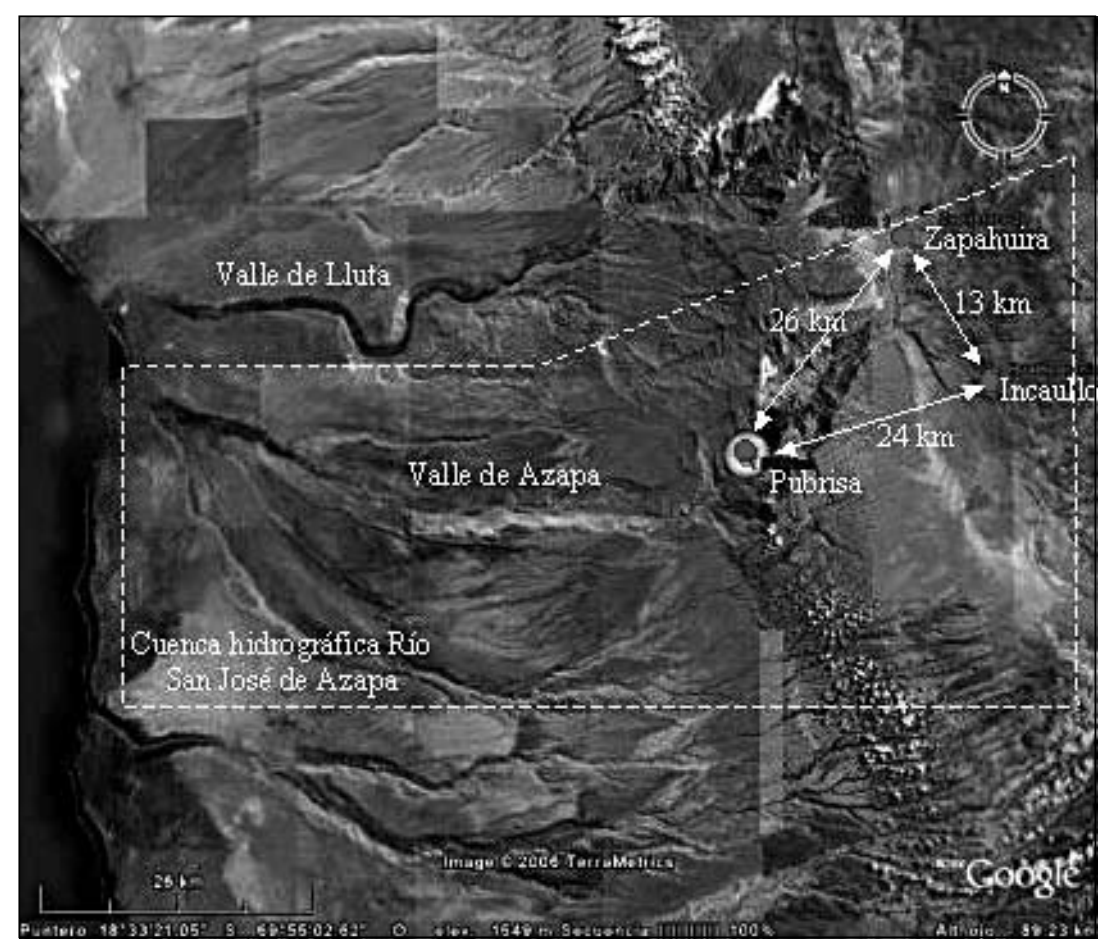

Figura 11. Nodos incaicos en la precordillera de Arica y su relación con el medio geográfico.

una ancestralidad estatal, el sol y el Inka como hijo del sol, desplazando el culto local.

Las plazas de Pubrisa, especialmente la segunda y la tercera, presentan recursos constructivos como gradas, mochetas y banquillos que remarcan la importancia de dichos espacios, le otorgan mayor significación a los accesos a ellos y a la actividad que allí se gestó. De este modo, las plazas de Pubrisa insertas en un plan de asentamiento preconcebido le otorgan al sitio un alto sentido religioso-administrativo. Pubrisa, por su ubicación y características debió ser un nodo de control inca del valle de Azapa, que debió actuar interrelacionadamente con otros nodos del sector, como Zapahuira en el sector del mismo nombre, e Incaullo en el valle precordillerano de Belén. Los dos centros mencionados se encuentran equidistantes de Pubrisa y los tres se ubican en la cuenca hidrográfica del río San José (Figura 11), situación que insinúa una acción integrada de los tres asentamientos para controlar y administrar al conjunto de aldeas y pucaras locales de esta cuenca hidrográfica.

\section{Comentarios finales}

Pubrisa fue planificado a través de una serie de áreas de actividad, cada una cumpliendo distintas funciones en el contexto económico y social de la comunidad (Figura 12).

En las unidades habitacionales se observó una clara organización de los espacios ocupados dentro del rol que cumplió el recinto, llámese lugar para comer, dormir y estar. A diferencia de éstas, en los recintos de mayor complejidad arquitectónica (p.e., la kallanka o Cabildo, el ushnu y plazas) hubo también una complejidad funcional mayor, ya que allí se desarrollaron actividades públicas y ceremoniales.

Las viviendas se componían de una sola habitación dividida en un sector para cocinar y comer, y otro para dormir; posiblemente en algunos sectores se construyeron casas de dos habitaciones, una de las cuales fue utilizada como cocina y la otra como cuarto para pernoctar. Dentro de la vivienda posiblemente habitaban todos los componentes de la unidad doméstica, los cuales dormían sobre el suelo, en un rincón del recinto.

El análisis de cada recinto obliga a pensar que las estructuras del poblado de Pubrisa tuvieron diversas funciones: desde espacios administrativos complejos hasta estructuras simples delimitados por un muro. 


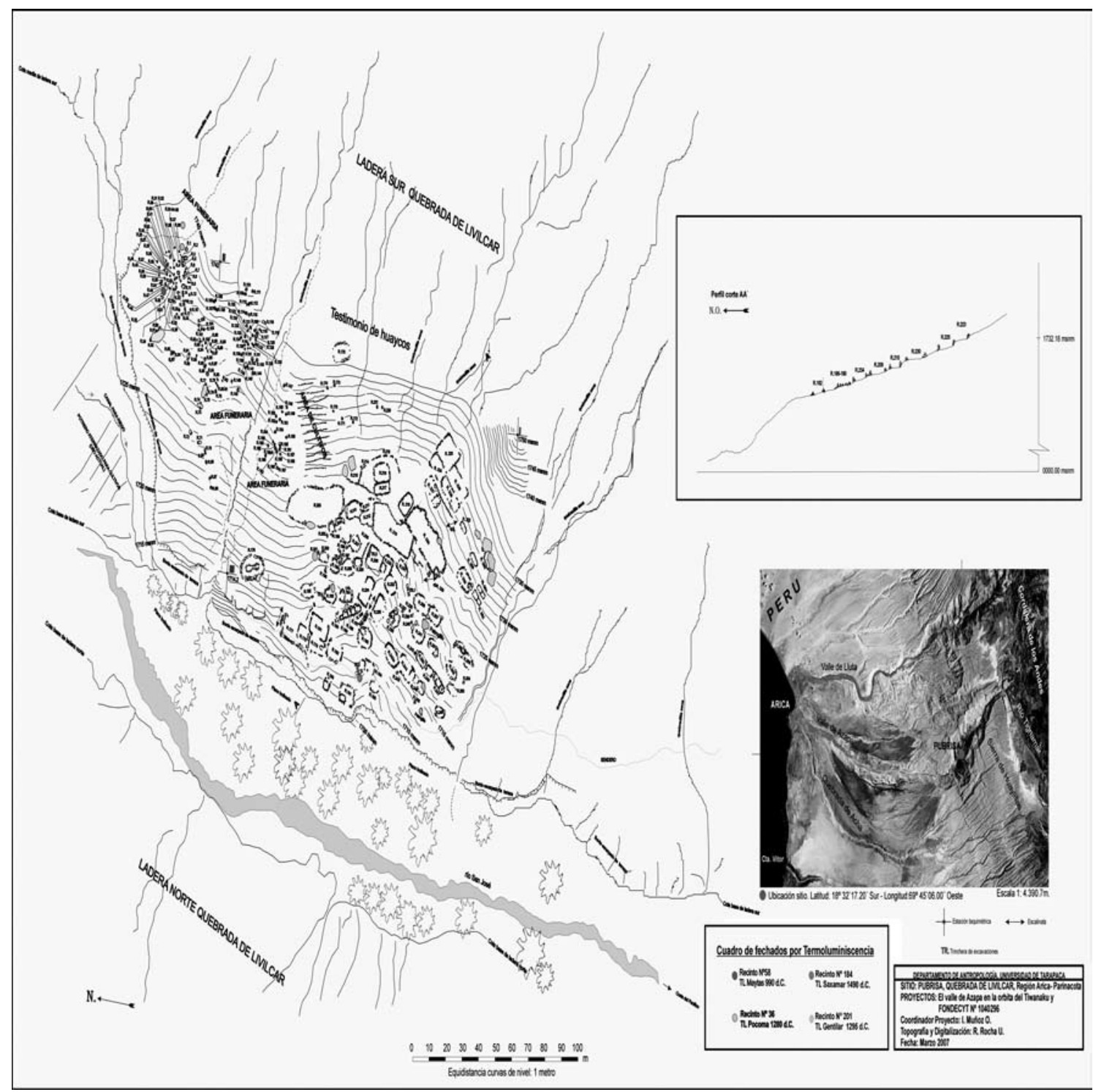

Figura 12. Levantamiento topográfico de Pubrisa.

En los recintos simples habitacionales, al parecer, vivieron los agricultores a diferencia de los recintos complejos de grandes dimensiones con estuco, donde se concentró el poder administrativo, incluyendo tal vez el representante del Inka. En estos lugares se realizaron ceremonias, como lo demuestran las hornacinas donde se pudieron haber depositado fetiches e ídolos a los cuales se les rendía culto. La población probablemente estuvo gran parte del día en sus chacras o terrazas de cultivos, lo cual permite suponer que sus habitaciones fueron para refugiarse en las noches. La comunidad al parecer tuvo una activa participación en los recintos de mayor convergencia social.
Pubrisa significa lugar de parada o de encuentro, lo que es coherente con el lugar donde se construyó el poblado, constituyéndose la toponimia en el primer nivel de conceptualización del espacio en el mundo andino (Martínez 1976). En este caso específico, la toponimia se refleja en la práctica, ya que a él o desde él llegaron y salieron una multiplicidad de senderos-rutas hacia distintos puntos cardinales, sugiriendo la importancia administrativa que pudo haber tenido el asentamiento en el contexto político y económico del valle.

Finalmente, es probable que la función de este poblado haya sido articular el tráfico de bienes y 
animales que circulaban desde la sierra a la costa, así como desde los valles costeños hacia el altiplano, ya que se encontraron evidencias de tráfico con los valles de Zapahuira, Chapiquiña y Belén, así como con la costa de Arica.

\section{REFERENCIAS CITADAS}

ADAN, L., 1999. Aquellos antiguos edificios. Acercamiento arqueológico a la arquitectura prehispánica tardía de Caspana. Estudios Atacameños 18: 13-33.

ADAN, L. y M. URIBE, 2005. El dominio inca en la localidad de Caspana: Un acercamiento al pensamiento político andino (río Loa, norte de Chile). Estudios Atacameños 29: 41-66.

ALDENDERFER, M. (Ed.), 1993. Domestic architecture, ethnicity and complementary in the South-Central Andes. University of Iowa Press, Iowa.

ALDUNATE, C., 2001. Arquitectura y poder. En Tras las huellas del Inka en Chile, pp. 45-51. Museo Chileno de Arte Precolombino, Santiago.

ALDUNATE, C., J. BERENGUER y V. CASTRO, 1979. La función de las chullpas en Likán. Actas del VIII Congreso de Arqueología Chilena, pp. 129-174. Sociedad Chilena de Arqueología, Universidad de Chile. Valdivia (1978).

BARBA, L. y L. MANZANILLA, 1987. Superficie/excavación. Un ensayo de predicción de rasgos arqueológicos en Oztoyohualco. Antropológicas I: 19-45.

BARBA, L. y J. CORDOVA, 1999. Estudios energéticos de la producción de cal en tiempos teotihuacanos y sus implicaciones. Latin American Antiquity 10 (2): 168-179.

BOUCHARD, J. F., 1983. Contribution a l'étude de l'architecture Inca. Editions de la Maison des Sciences de l'Homme, París.

CHACAMA, J., 2005. Patrones de asentamiento y uso del espacio. Precordillera de Arica, extremo norte de Chile, siglos $\mathrm{X}-\mathrm{XV}$. Bulletin de l'Institut Français d'Etudes Andines 34 (3): $357-378$.

FLANNERY, K., 1976. The early Mesoamerican village. Academic Press, Nueva York.

GASPARINI, G. y L. MARGOLIES, 1980. Inca architecture. Indiana University Press, Bloomington y Londres.

ISBELL, W., 1997. Mummies and mortuary monuments. A postprocessual prehistory of Central Andean social organization. University of Texas Press. Austin.

KAULICKE, P. y W. ISBELL (Eds.), 2001. Huari y Tiwanaku: Modelos versus evidencias. Boletín de Arqueología PUCP 4.

KOLATA, A. (Ed.), 1989. Arqueología de Lukurmata 2. Centro de Investigaciones Antropológicas de Tiwanaku, La Paz.
MANZANILLA, L. (Ed.), 1986. Unidades habitacionales mesoamericanas y sus áreas de actividad. IIA/UNAM, México D. F

MARTINEZ, G., 1976. El sistema de los uywiris en Isluga. En Homenaje al Dr. Gustavo Le Paige, pp. 255-327. Universidad del Norte, Antofagasta.

MUÑOZ, I., 2004. Ocupación del espacio doméstico y áreas de actividad generadas en el asentamiento prehispánico de San Lorenzo. Diálogo Andino 24: 53-98.

2005. Espacio social y áreas de actividad en asentamientos agrícolas prehispánicos tardíos en la sierra de Arica. Bulletin de l'Institut Français d'Etudes Andines 34 (3): 321-355.

MUÑOZ, I. y J. CHACAMA, 2006. Complejidad social en las alturas de Arica: Territorio, etnicidad y vinculación con el Estado Inca. Ediciones Universidad de Tarapacá, Santiago.

MUÑOZ, I. y M. SANTOS, 2000. Relaciones y estrategias de asentamientos humanos en el poblado prehispánico de Pubrisa, Arica: Análisis del espacio habitacional y de la alfarería. Pacarina X: 6-48.

MUÑOZ, I., J. CHACAMA y M. SANTOS, 1997. Tambos, pucaras y aldeas. Evidencias del poblamiento prehispánico tardío y de contacto indígena-europeo en el extremo norte de Chile: Análisis de los patrones habitacionales y nuevas dataciones radiométricas. Diálogo Andino 16: 123-191.

NIELSEN, A., 2006. Plazas para los antepasados: Descentralización y poder corporativo en las formaciones políticas preincaicas de los Andes circumpuneños. Estudios Atacameños 31: 63-89.

SCHIAPPACASSE, V. y H. NIEMEYER, 2002. Ceremonial Inca Provincial: El asentamiento de Saguara (cuenca de Camarones). Chungara, Revista de Antropología Chilena 34 (1): 53-84

STARKER, L., 1967. El desierto. Ediciones Offset Multicolor, México D.F.

WILK, R. y W. ASHMORE (Eds.), 1988. Household and community in the Mesoamerican past. University of New Mexico Press, Albuquerque.

WILLEY, G., 1953. Prehistoric settlement patterns in the Viru Valley, Perú. Bureau of American Ethnology, Smithsonian Institution, Washington D. C.

ZUIDEMA, T., 1989. El ushnu. En Reyes y guerreros. Ensayos de cultura andina, M. Burga (Comp.), pp. 402-454. FOMCIENCIAS, Lima. 